\title{
Customer relationship management in practice - A qualitative study
}

Date received: 11th January, 2001

\section{Julie Abbott}

is the Influencer Marketing Manager for IBM's Global Business Intelligence Solutions EMEA, working with industry analysts and a number of European business schools. Before becoming a marketer in 1995, Julie was a systems engineer specialising in IBM's own mainframe technologies. Julie graduated from IBM's own marketing school and holds the Chartered Institute of Marketing's (CIM) post-graduate Diploma, and a Masters in Marketing from Manchester Business School. She is a full member of CIM and a Chartered Marketer.

\section{Merlin Stone}

is IBM Professor of CRM, Bristol Business School, UK; Executive Consultant, Business Innovation Services, IBM; Director, QCi Ltd. and Swallow Information Systems Ltd. He is the author of 20 books and many journal articles on CRM and related topics. His research focuses on definitions, strategies and models of customer management, success and failure in implementation of new approaches to customer management, the relationship between e-business and customer management, and data protection and privacy issues.

\section{Francis Buttle}

is Littlewoods Professor of Customer Relationship Management, Manchester Business School, UK. He has nearly 30 years' experience in marketing management, education, consultancy and research. He has lived and worked on three continents Europe, Australasia and North America and has published over 180 items including three books. His most recent book, published in 1996, is an edited volume on the theory and practice of relationship marketing. His teaching and research interests include customer retention, service quality, customer relationship management and management in service industries.

Abstract This paper reports the results of a qualitative study into the implementation of data-driven customer relationship management (CRM) strategies. Seventeen companies are investigated and three short case studies are presented. It is found that clean customer data are essential to successful CRM performance and that technological support for data acquisition, analysis and deployment are not widespread. Clean customer data enable CRM strategies to be both more effective and more efficient, yet not all companies are investing in improving data quality.

\section{INTRODUCTION AND METHODOLOGY}

The paper examines in depth the state of customer relationship management (CRM) in a number of companies, the majority comprising IT companies.

Others include a new business start-up, a not-for-profit organisation, utilities, manufacturing, luxury goods, services, petroleum and a marketing consultancy.
The research focuses on three areas: database, CRM and general marketing.

\section{Research question}

The authors' basic research question was as follows:

To what extent are companies collecting, storing and manipulating
Tel: 01788891 349; e-mail: abbotj@uk.ibm.com 
customer data in order to develop and implement more effective CRM strategies?

The research was conducted in two stages, an e-mail survey of 40 respondents from UK industry and follow-up face-to-face or telephone interviews with a sub-sample of 17 e-mail survey respondents. An earlier issue of this journal carries a report on the quantitative stage of this research (Stage 1) as well as on the research methodology. ${ }^{1}$ This paper, however, reports the findings from Stage 2 of the research. The Stage 2 work was designed to elicit more qualitative insights into CRM implementations. Three informants gave their permission to write short case studies. These are included towards the end of this paper. Some additional research was done via the Internet to enhance the case study data. Our methodology was guided by Yin's recommendations for conducting qualitative research. ${ }^{2}$ Further details of the research methodology appear in the authors' earlier paper. This paper reports the general findings from the 17 follow-up interviews, supported by insights provided by particular illustrations.

\section{DATABASE/DATA MANAGEMENT}

The goal here was to understand better the content and deployment of marketing databases within companies. Access, data accuracy and how the database is populated were considered.

\section{Successful campaigns due to better data and the long-term view}

The overwhelming finding was that segmentation and targeting of customers and prospects based on clean and accurate data are the keys to success
- regardless of the campaign tactics employed. There were examples of inaccurate data causing expensive wastage and a marked lack of success, and others of enhanced effectiveness and efficiency based on reliable customer data. An employee of a database-marketing agency cited savings of 'over 250 per cent' by using good quality data. He advised investment in cleaning and improving the accuracy of the database. Databases, he suggested, should be based on customers rather than products and should precede profiling and targeting activity. This strategy can give major increases in campaign responses and a return on investment of between 400 and 1,200 per cent depending on the industry and campaign type.

The main campaign types benefiting from better data are direct mail and Web (viral) campaigns. All of the successful campaigns mentioned by respondents were highly targeted and the majority also returned more data that were used to improve the database still further. For example, a luxury car manufacturer's product launch campaign employed Web advertising, coupled with mailing to current customers, then a product brochure timed to arrive on the morning of the launch.

Respondents cited a number of campaigns specifically to collect data. These mainly took the form of incentives, questionnaires and website registrations. Others included making sure that call centres got the correct information on the customers, data cleaning exercises (often through third parties that can tele-clean) and making sure that responses from all campaigns were added to the database (and that these campaigns generated the correct data needed).

All of the respondents agreed that better data is one, but not the only, key 
to success of marketing in the future. How the data are used and understood is also crucial, along with the correct analytical tools. Individual comments included:

- 'People don't understand how critical data is yet'

- 'Knowing how to use data and exploit it for marketing terms is the issue'

- 'Data gives us an edge'

- 'We also need the people with the right skills around the data'.

\section{Database usage}

Few of the respondents actually accessed the database themselves. It was either a task for another department or someone who worked for the respondent.

Monitoring data accuracy is therefore difficult. Regardless of who actually accesses the database, the reasons for access varied from campaign-specific information (usually to segment/target) through to analysis, tracking and cleaning. The quality of the data appears to be improving slightly over time. However, marketers' expectations are increasing at a faster rate, giving the impression that the data are actually less accurate than before. A minority of respondents was happy that their data were clean and accurate. They were in the luxury goods and not-for-profit sectors, where traditionally target markets are smaller. One respondent from a services company had just finished a successful major exercise to increase data accuracy, based on an incentive mailing to the customer base.

It is typically the marketing and front-line customer-facing departments (such as sales and customer service) who are responsible for changes to the data, the momentum of which has increased since the inception of CRM. Some CRM proponents advocate the sharing of some customer data between companies in the same industry (for example, on 'bad' customers), but this practice is not yet widespread. None of the respondents admitted to doing this, although some share basic data with business partners, usually for joint marketing purposes. However, one respondent in the utilities sector mentioned a governing body that insists on customer data being passed across if customers move utility suppliers.

\section{Technologies and tools employed}

Around half of the respondents have implemented new technology to aid data collection or run their campaigns, with the balance trying to make better use of what they already have. The technologies are a mix of new databases, data warehouses and marts, call centres, campaign managers, data analysis tools (such as OLAP and mining) and data capture facilities (scanners etc). E-mail, Internet and other electronic communications (such as Lotus Notes-based team rooms) were also reported.

Surprisingly, perhaps, it is the non-IT companies that have invested in technology to help with marketing. Table 1 shows the number of affirmative answers given by the respondents (17 in total) to a question asking which technology-based marketing tools they used today, were aware existed and had used in the past. As expected, spreadsheets were ranked top, but the Internet also shared this position. Call centres were next, but the specific tools designed to help marketers to be more effective (campaign managers and data analysis tools) and make better informed decisions, were ranked lower. This perhaps shows that budget holders still 
Table 1: Technology tools employed to help marketing

\begin{tabular}{lcccc}
\hline & Use today & Are aware of & Have used in past & Rank \\
\hline Campaign manager & 4 & 13 & 7 & 8 \\
Spreadsheets & 16 & 17 & 17 & 1 \\
Personalised print & 10 & 16 & 13 & 4 \\
Data mining & 9 & 16 & 11 & 5 \\
OLAP & 7 & 16 & 8 & 7 \\
Call centre & 12 & 17 & 17 & 3 \\
Internet & 16 & 16 & 10 & 1 \\
Planning & 8 & & & 6 \\
\hline
\end{tabular}

do not accept what marketers can achieve with the right tools.

\section{Data improving routes to market and CRM}

Having more (and in some cases better) data has enabled companies to adjust their routes to market. Customers are matched with the best channel for both their, and the company's, needs. For example, lower value customers are serviced through lower expense channels, such as telesales or business partners rather than field sales. This cuts the expense-to-revenue ratios, enabling the field force to concentrate on the high yield customer base, increasing profits while maintaining coverage across the entire customer and prospect base. Some companies have always worked in this way so no change has been necessary. Younger firms have embraced new channel technologies, such as Web and call centres from the outset and so have not made any changes.

As the data quality improves, databases are playing a greater part in CRM implementations. Virtually all the respondents acknowledged this. Some maintained that the database underpins the whole CRM enterprise. They also suggested that their own databases had some way to go before the theory of CRM and the practice meet, but that efforts were being made to move forward as fast as possible. Some commented that the database and communications around it needed improving dramatically before it would be effective.

\section{CRM}

The authors' goal here was to understand both the marketer's and the company's viewpoints regarding CRM and whether they felt they were adequately prepared. (All of the respondents were implementing or already using CRM.)

\section{The database}

Having agreed that the database is an integral part of CRM, only four respondents said their databases would not need changing. Most noted that significant changes would be needed. The nature of this change varied, from simple cleaning to adding to the complexity of the data (for example, adding new areas of information such as wallet share, derived attributes and behavioural data). More flexibility was needed along with better structures and more simplified access.

Although most of the respondents identified different areas for change, the consensus position was that the databases did not hold the right type of information to allow marketers to understand their customers well enough 
to segment and target them properly. This problem also adversely affected the strategies and tactics employed. Half of the companies had started to make changes to the database, mainly by aiming to understand what was needed and then looking for sources of missing information. Some felt that a culture change was needed to really make this happen on the scale needed, and that it was happening in too small a way today.

\section{Channel changes}

Over 50 per cent of the respondents said that there would be no changes to channels linked to the implementation of CRM. Some did not know but the rest (around 35 per cent) said that changes were taking place. These were mainly in the area of value - eg low value customers moving to low value channels or special personal service for high value/top customers, call centre implementation and usage of business partners for fulfilment. The channel strategies were being reviewed and better use of technology (Web/telephone) for customer dialogue was starting to be used.

\section{Personal beliefs}

The respondents were asked what could be done as far as data and CRM were concerned in their company to ensure greater marketing success. Three main themes stood out:

- Understand and get closer to the customer base, see them as individuals. A corporate/company culture change may be needed to do this.

- Quality of the data and database and the commitment from the top to ensure this happens. This included using the latest technology to analyse the data and access the customer and prospect base.

- Make marketing more pervasive across the company. Marketers need to get out of their individual areas and talk to others to gain credibility and make sure that messages are consistent; this again may need a culture change.

All of the answers showed that things needed to happen and commitment was needed from people at the top of the company to ensure that it did. Some respondents were in a position to push harder for change than others. This was shown by the answer to the next question - 'Are you being held back in any way on this?' Funding and executive commitment to database development and CRM are the main barriers to change that marketers are experiencing. Some respondents felt that time was also an issue - mainly because other areas of the business took priority.

Everyone believed in the importance of CRM to some degree, the differences being whether it is right for that particular company, industry or marketplace. One informant said: 'It depends very much on the business and need, rather than being a universal panacea.' The respondents were asked if their company was implementing CRM because they genuinely believed in putting the customer first (assuming profits would follow), or if it was being implemented for reasons internal to the business. All but the not-for-profit organisation and start-up company said the latter.

\section{GENERAL MARKETING}

The authors' goal here was to find out how respondents would like to see marketing change in their company. The answers differed widely but most could 
be given a CRM interpretation. It was felt by many that marketing must be accepted across the company as the core strategic force for the business rather than short-term sales support. Marketing has to show it adds value in order to be taken seriously and permeate the whole business. Customer relationships and channel strategies should be re-examined, and integrated marketing communications deployed across channels. Finally, worries about data quality need executive attention for some respondents, with the correct enablers and funding put in place to ensure fast improvement. This means better technology to access the data, analyse them and drive campaigns.

\section{CONCLUSION}

Although companies are beginning to embrace CRM, there is much room for improvement. Some companies are more advanced than others. These tend to be newer companies operating in niche markets where there is a lot of choice for the customer. Larger, established, mainstream players find the changes harder to make and, although the principles of CRM are accepted as sound, the practical implementation moves at a much slower pace.

Many of the respondents queried whether their companies were adopting CRM really for the benefit of customers (in the confident belief that profit would follow) or as a 'me too' strategy to combat competition. There was a widespread belief in CRM but with an acceptance that the customer would know which companies really cared about them and which were paying lip service to the concept. Overall, most of the companies were moving to improve their data and customer focus. Marketing is not highly regarded in the slow-to-adapt companies.

\section{THREE SHORT CRM CASE STUDIES}

This section contains three short case studies from survey respondents. The individual cases were chosen because of their diversity and relevance to the research question. Names have been removed to preserve anonymity where requested.

\section{Case study 1 - start-up company}

This case reports a new business start-up. It focuses on the beliefs of the board members in respect of customer data, CRM and customer service.

\section{Introduction/background}

This company was set up two years ago under the Young Enterprise Scheme. It is based in a school near London. There are five board members. All but one was studying for GCSE exams at the time of the research. The exception is the managing director's father who is in business separately. $\mathrm{He}$ is on the board only to take on any activities that have to be performed by someone over 18 . Everything else, including all business decisions, is undertaken by the teenagers. The company employs several sales representatives in the same age group. They are friends of the board members and work for the company part-time.

The company's mission is to set up and run websites for customers. At present, the operation is based in and around London due to time and travel restrictions. The board members are not old enough to drive and must rely on public transport. However, the sales reps are based in major cities across the UK and Ireland as well as Brussels, Paris, Berlin and Jerusalem. The company has a turnover of between $\mathcal{f}^{1}$ and $\mathcal{E}^{2}$ million and is making a profit. 


\section{Business philosophy}

This is a very young company run by young entrepreneurs who are trying out their business wings. They practise what they learn from the textbooks in their economics and business studies classes and therefore understand (and believe) the theory of CRM and use it daily in their business. They started with a penetration pricing policy to enter the market. They have experienced a sales growth rate of 40 per cent per annum across the two years that the company has been in existence. This growth is expected to slow now. They are committed to customer service as their sales director said: "We are a small company so we have to focus on service, and when we look after our customers it does help business'.

\section{Products/services}

The company designs, establishes, promotes and hosts websites for customers. There is a Web design team of five who have a capacity of 15 websites a month (depending on complexity and time/exam constraints).

An external company is subcontracted if demand cannot be fulfilled.

\section{Business/marketing strategies}

The main strategy is to develop relationships with their customers. This promotes repeat business and recommendations. The board is in the process of launching a parent company to the three companies in their portfolio, one of which aims to be the first no-monthly-fee Web hosting service in the UK. A major review of business and marketing strategies had just taken place. This review enabled the board to study customer feedback and data and decide how best to move forward to achieve their business goals of increasing awareness and entering new markets, while giving the best service to their existing customer base in order to retain them. The result of the review was that the company planned to rebrand and relaunch in September 2000 when it planned to diversify into new markets.

\section{Financial objectives}

The main objective is to have profits increase by 10 per cent year-on-year. Sixty per cent of this increase will be retained into a company university and car fund for the directors. The remainder is to be reinvested into the company.

\section{Measurement}

The company measures its performance in terms of customer satisfaction, sales, revenue and whether it is meeting its profit objectives.

\section{Markets}

Today, half their customers are in and around London. They market to small and medium businesses that want to go on the Internet. However, the company targets customers worldwide and, as two of the board are multilingual, websites can be set up in German and French as well as English. The remainder of the customer base is in the rest of the UK and mainland Europe - accessed due to contacts made when two of the board members lived there. The USA is a future target market.

\section{Customer profile}

There are 18 repeat customers on the books, who have had their sites updated or bought new sites. Most of the customers pay a variable monthly fee dependent on the services they use. Most customers are small- to medium-sized 
businesses with a sizeable number being start-up companies. Others are individuals who want their own website built and 'dot.com' companies.

\section{Routes to market}

The main channels are their sales force, website (including e-mail) and promotions. They also make use of the telephone and have face-to-face meetings whenever possible. The employees of the company are all based at their family homes, although the directors do work from school occasionally.

\section{Marketing tactics}

Campaigns are based on the Web especially those asking for responses from prospective and existing customers - in order to get better data. Telephone promotions are also used. Other promotions include linked websites, e-mailshots and attending a small number of trade fairs (maximum of two per annum.) Marketing spend is quite low — no details were given.

\section{Data/database usage}

The database is company-wide, holding a variety of data - including customer and company data, customer feedback, personal information, buying patterns and competitor information. There is also general information on the markets. The directors each access the database on a 'need to know' basis - exam constraints stop this happening more often, although there will be an annual review and analysis of the database in the summer holidays. At the moment, the data are mainly used to look for new markets and improve customer service, but the board believes that its data can be used in a better way and this was to be part of the summer review. The data are seen as being very useful in order to facilitate business decisions and market in the most effective way possible. Data are employed mostly in the planning process and to review previous campaigns and services. This usage allows the board to enhance services where necessary and put the most relevant marketing and sales tactics in place.

\section{Conclusion}

The team are committed to giving a personal, tailored customer service as well as sustaining growth in their company. They realise that in order to achieve the latter (and make profits), they must concentrate on the former, making sure that after sales service and contact is as good as pre-sales. They are a very impressive team and have already achieved a lot in their first two years of trading, as well as keeping up with their studies and plans for university.

\section{Case study 2 - not-for-profit}

This case concentrates on database matters as they influence the CRM strategies of a not-for-profit organisation. The information was supplied by the marketing director.

\section{Background}

This ecological organisation relies on supporters in their subscriber database for revenue. Since 94 per cent comes from individuals, the marketing department is dedicated to meeting these supporters' needs. Direct debits are the most common method of payment (70 per cent of subscribers) and a paperless direct debit system was recently set up which passed the stringent scrutiny of the clearing banks. The organisation was the first in the sector to take paperless direct debits. 


\section{The database}

The database was moved from card index files to computer in 1982. A lot of the original data were still in existence until fairly recently, causing problems due to the constraints imposed by 1980's technology (eg null fields full of asterisks). These data have now been cleaned and the constraints removed. All new data entered use a comprehensive set of rules to ensure accuracy and allow flexibility. For example, new subscribers will be asked for date of birth rather than age, as well as telephone number and any e-mail address. Whenever anyone talks to a subscriber, the current details are checked and reconfirmed. As the organisation is entirely dependent on the data they are forced to keep revisiting the data integrity.

\section{The database team and technology}

The marketing database team set the data objectives. They are very focused on getting the right data and using appropriate forms of analysis. They use the latest technology including data mining, analysis and e-commerce. Only data that are necessary and can be made use of are collected, and this is under constant review by the team. A good team is considered vital as it vastly improves the understanding of the information held within the database. The team keeps abreast of technology to ensure continued success, for example, the re-engineering of the database to allow the validation and change of e-mail addresses. As external agencies are used for telemarketing, excellent e-commerce facilities are necessary. E-mail is the primary communications method between the organisation and the agency, and is becoming more important in contacting subscribers.

\section{CRM}

The database is essential to the organisation's CRM strategy. It is used to maintain supporter relationships and slow attrition, which are two significant drivers of revenue, and achievement of the not-for-profit goals. The organisation has always worked in this way and the database was built around this understanding. Genuine care for supporters is what drives the organisation and it would be unacceptable to employ CRM strategies for business reasons alone. CRM is something they believe in but think that the expectations are too high today and it is set for failure. They believe that the CRM ethos is strong in this organisation, but that companies generally need to be realistic about what can be achieved. In this organisation, everything must be more tailored to the individual subscriber as they are totally dependent on their supporters and must meet their needs.

\section{Issues}

The main issue is that of budget.

Keeping the database up-to-date has a low priority as supporters want their contributions to go to mainstream campaigns. Salaries are another concern as they are lower than within industry. People who are there typically want to work for the organisation because they subscribe to the ideals. (This can also be a benefit as everyone will be working together towards the same goals.)

\section{Differences from the commercial sector}

The marketing director has some experience of the for-profit sector. Marketing gives confidence to the other parts of the organisation by delivering the vision and receiving the subscriptions. This also adds a lot of value and makes it easier to open up 
internal communications channels. $\mathrm{He}$ believes that the commercial sector still has a problem with marketing as it is not seen to have value, credibility or trust, and marketing's objectives are often dissimilar to other departments within a company.

\section{Case study 3 - luxury goods manufacturer}

This case focuses on the role of data in yielding CRM success.

\section{Background}

This manufacturer of high-value luxury goods has been in business since the early days of the 20th century, is based in the UK and relies on a worldwide network of dealers as its route to market. Its name epitomises high-quality motoring and, although it has recently been the subject of a takeover, and therefore has new objectives (production rising from 1,200 to 15,000 units a year), it is still reliant on its small customer base at present.

\section{Customer base}

The customer base is global but quite small and niched. Customers are wealthy individuals or companies who use the goods to make a statement about their own brand (for example, the Peninsula Hotel in Hong Kong). Many customers own several residences and have a lifestyle that includes yachts, aeroplanes and even their own sports teams. The company partitions customers into two segments: the main customer base and key accounts (top customers, including some of the world's richest people). It treats those buying new and used goods in the same way. Most purchasers of new goods were once owners of used goods. The rebuy cycle ranges from once every
20 years to several purchases in a single year.

\section{Customer relationships}

Customer relationships are paramount for this company. This is accepted at every level in the organisation, with all employees taking a great pride in their workmanship and ensuring the highest quality product and service. After-sales service is as important as pre-sales because customer loyalty is a high priority, with repeat purchases as the target. The customer service line goes direct to the experts at the manufacturing plant to ensure that the customer gets the right answer first time. The company makes sure that they know enough about their customers to ensure the correct type of service and offers are given. Product launches are executed in a personalised way, to ensure the best response. Personal managers are also employed from other luxury goods companies whose sole job is to interact with the customers. A benchmarking exercise was recently undertaken to measure performance against aspirational brands and companies (eg Krug, David Linley, Amex Black Card etc).

Many customers live in the Middle or Far East. Different cultures and conventions present challenges to the customer service team as they ensure that the highest quality service is given without adversely impacting cultural sensitivities. For the marketers, one problem that arises is simply that of names. From an occidental perspective, customers in the Middle East often have long and complex names and it is crucial to get them right. Customers are proud to own the products and are very loyal to the company, therefore, knowledge of them is critical and data are fundamental to this. 


\section{Data as a factor in CRM}

The database is central to keeping the customer relationships. Accurate personal data are critical. Purchase histories are maintained for at least 20 years and this is being extended as more information is obtained. Each unique item manufactured in this time frame can be tracked. The database currently holds around 50,000 active customer records and 30-40,000 products. The company is now trying to go back even earlier with the ultimate aim of knowing the whereabouts and 'life' of each of the units manufactured by the company since its inception. The data are collected and kept up to date mainly by personal interactions with customers and dealers, as well as via campaigns and customer satisfaction surveys. Every respondent to the survey gets a personal letter of thanks or a visit from a customer manager. The database is used daily and any problems quickly addressed to ensure minimum disruption. There are no specific cleaning exercises done. Instead, customer records are dealt with on a personal basis.

\section{Comments}

This long-standing company genuinely cares for its customers and has learned over the years that it is critical to keep them loyal. Therefore, CRM has long been used and proven and this has been relatively easy with such a small set of high-profile customers. Time will tell if this strategy can continue once output increases tenfold and less costly products become part of the range. This change will open up the market and bring in a new set of customers who may need a different approach. The new owners of the company are mainstream and not used to dealing with customers in an individual fashion and this too may be a concern for the current employees of the company.

\section{Case study conclusions}

The three cases were similar in that the companies targeted customers who in the main were individuals or small businesses rather than large corporates. All three focused clearly on customer needs and delivery of high-quality service to exceed expectations and promote loyalty.

Although they were different in age and industry, they all served a niche market, which is something that larger, mass-market companies find more difficult to do due to the size of their customer base. However, it is likely to become more necessary as customers become more sophisticated and the Internet channel expands, bringing with it a huge increase in the amount of data collected.

\section{References}

1 Abbot, J. L., Stone, M. and Buttle, F. (2001) 'Integrating customer data into customer relationship management strategy: An empirical study', Journal of Database Marketing, Vol. 8, No. 4, pp. 289-300.

2 Yin, Y. K, (1994) 'Case study research: Design and methods', Applied Social Research Methods Series, Vol. 5, rev. ed., Sage Publications, Newbury Park, CA. 